Maria Flávia Gazzinelli 1

\title{
A interdição da doença: uma construção cultural da esquistossomose em área endêmica, Minas Gerais, Brasil
}

Andréa Gazzinelli 1

Regiane Veloso Santos 1

Luiz Alberto Oliveira Gonçalves 2

\author{
The interdiction of disease: a cultural \\ construction of schistosomiasis in an endemic \\ area in Minas Gerais, Brazil
}

1 Escola de Enfermagem, Universidade Federal de Minas Gerais. Av. Alfredo Balena 190 Belo Horizonte, $M G$ 30130-100, Brasil. flavia@enf.ufmg.br andreag@enf.ufmg.br 2 Faculdade de Educação, Universidade Federal de Minas Gerais. Av. Antônio Carlos 6627, Belo Horizonte, $M G$ 31270-901, Brasil. laog@fae.ufmg.br

\begin{abstract}
This study was conducted in a rural area endemic for schistosomiasis in Minas Gerais, Brazil. The objective was to determine the relationship between an environmental and health education program for schistosomiasis, implemented for teachers and students from the state secondary school in the village of Boa União, and the subsequent actions of its participants in regards to the environment and the illness. An important difference in this program is its perspective that it is not merely the implementation of instrumental and cognitive knowledge of the environment and illness, but an approach in which subjects are asked to question and investigate their perception of reality, the environment, and the illness. The study demonstrated that a change in attitude could occur from reflection on one's experience in relation to both the environment and diseases endemic it.
\end{abstract}

Key words Health Education; Environmental Education; Schistosomiasis

Resumo Desenvolvido em uma área endêmica em esquistossomose, zona rural de Minas Gerais, Brasil, este estudo pretendeu analisar a relação entre um Programa de Educação Ambiental e Saúde, e a postura dos sujeitos frente aos ambientes e à doença. O programa de educação implementado, destinou-se a professores e alunos da escola estadual do lugarejo de Boa União. Pautou-se em um importante dispositivo diferencial com relação aos programas mais usuais neste campo educacional, ao buscar uma perspectiva não puramente instrumental e cognitiva de conhecimento da realidade e da doença, mas uma abordagem na qual os sujeitos são levados a indagar e investigar juntos as suas percepções da realidade, dos ambientes e da doença. Ficou demonstrado que é a partir do conhecimento e reflexão acerca da experiência dos sujeitos com os ambientes e com a doença, experiência entendida aqui como campo onde se entrecruzam representações e práticas, aspectos objetivos e subjetivos, o racional e o empírico, que se obtém o confronto e ruptura cognitivos indispensáveis a uma mudança de postura dos sujeitos.

Palavras-chave Educação em Saúde; Educação Ambiental; Esquistossomose 


\section{Introdução}

A intervenção educacional em áreas endêmicas é freqüentemente tratada no campo da educação e saúde, apoiada na idéia de que se pode educar para saúde. Esse princípio de se educar para saúde, usualmente voltado para populações pobres e desfavorecidas sócio-econômica e sócio-culturalmente, parte da hipótese de que vários problemas de saúde são resultantes da precária situação educacional da população, carecendo, portanto, de medidas "corretivas" e/ou educativas.

Tal hipótese levou à utilização, na prática pedagógica em saúde, de recursos teórico-metodológicos ligados à idéia de que a aquisição de conhecimento sempre levaria à adoção de novas posturas e práticas. Decorre daí que os programas de saúde tomaram para si o objetivo de substituir falsas crenças por conhecimento acurado. Quando isso acontece, via de regra, a educação se torna normativa (Gastaldo, 1997).

Assim, as ciências ou o ramo delas que se ocupam das medidas "corretivas" e/ou educativas, teriam como missão modificar os indivíduos por meio de uma intervenção pautada na idéia de que os conhecimentos devam vir sempre "de fora", de algum lugar, de alguém; de interesses predominantemente instrumentais e de atitudes que privilegiam a verdade das proposições sobre um fenômeno (dimensão cognitiva), em detrimento da dimensão expressiva da subjetividade (afetiva). E, finalmente, pautada no modo de pensar a ciência como autônoma, como capaz de dar conta de todos os problemas do homem - idéia fortemente criticada, hoje, pelas perspectivas não formalistas da ciência que referem ao pensamento de Bachelard, Kuhn, Feyerabend e outros que revelam os limites do conhecimento científico enquanto conhecimento histórica e socialmente determinado.

Isso significa dizer que os projetos que emanam dessas circunstâncias acabam tratando o público como o objeto da transformação. Assim, não seriam as situações de desigualdade que deveriam mudar, mas as pessoas. É nesse contexto que se concebe uma "ação específica para", ou seja, uma "educação para saúde”. Imaginase sempre que na ponta (no para) está alguém que não consegue agir como sujeito de sua ação.

O presente estudo teve como objetivo investigar uma experiência concreta na qual a relação entre a educação e a postura dos sujeitos frente à doença foi efetivada mediante uma proposta de intervenção, envolvendo professores e alunos de uma escola pública de ensino fundamental, sediada em uma região onde a es- quistossomose se apresenta como endêmica. A referida intervenção ocorreu sob a forma de um Programa destinado ao enfrentamento de um dos graves problemas de saúde pública brasileiro, a saber, a incidência e prevalência da esquistossomose entre as populações que vivem em áreas de risco.

No Brasil, a área endêmica para esquistossomose se encontra em expansão, abrangendo 19 estados com aproximadamente 26 milhões de habitantes expostos ao risco de infecção e cerca de 2,5 milhões de pessoas infectadas (FUNASA, 1999). Embora exista tratamento eficiente para a esquistossomose, seu controle é complexo, exigindo a atuação de serviços de saneamento básico, educação, bem como outras medidas de cunho técnico-político. Em área endêmica, a esquistossomose se desenvolve cronicamente, com manifestações, de um modo geral, benignas. Alguns indivíduos, após a exposição, podem apresentar manifestações cutâneas do tipo urticária, porém, não apresentam o quadro agudo característico da doença. Em poucos casos ocorrem manifestações graves, como a hepato-esplenomegalia, varizes esofagianas com sangramentos freqüentes. As formas mais graves podem ser fatais.

\section{Metodologia}

\section{Local}

Este estudo foi desenvolvido na localidade rural de Boa União, Município de Itabirinha de Mantena, situado no nordeste do Estado de Minas Gerais, em área endêmica para esquistossomose, cujos índices de prevalência estão em torno de 70\% (Correa-Oliveira, 1994). Boa União possui uma população de aproximadamente 1.800 habitantes. A principal fonte de renda é a agricultura. Trata-se de uma vila majoritariamente habitada por moradores de baixo poder aquisitivo. Com relação às moradias, aproximadamente $80 \%$ delas possuem água proveniente de cisterna. O nível educacional é baixo, com um grande número de analfabetos ou com o primeiro grau incompleto.

\section{Sujeitos}

A Escola Estadual João Amâncio Sobrinho, única escola de Boa União, conta com um corpo docente composto por 25 professores, diretor e vice-diretor, provenientes da própria comunidade ou de áreas vizinhas, e cerca de 500 alunos matriculados no pré e ensino fundamental (1a a 8a séries) divididos em turmas de aproxi- 
madamente trinta alunos. O Programa de Educação foi desenvolvido junto a aproximadamente 250 alunos e sete professores, com diferentes níveis de graduação (um professor leigo, três com magistério e três com licenciatura do tipo emergencial). O Programa foi dirigido para os alunos cursando da 3a a 8aséries, com idades que variavam de 11 a 20 anos, pois, neste estágio, presume-se, apresentam maior capacidade de verbalização e algum domínio sobre a língua escrita. As atividades e conteúdos eram ajustados de acordo com a série do aluno. Os professores foram escolhidos de acordo com sua disponibilidade e com a intenção dos pesquisadores de se formar uma equipe multidisciplinar. Os sete professores da escola receberam uma bolsa-auxílio fornecida pelo Projeto, já que havia a necessidade de, junto com a atividade de ensino, desenvolver também a de pesquisa, com a equipe de pesquisadores.

\section{Desenho do estudo}

O programa de educação proposto inseriu-se em Projeto de Pesquisa interinstitucional no qual se encontravam integrados diferentes campos de conhecimento. Seguiu, em linhas gerais, o modelo da chamada Pesquisa-Ação, uma vez que reforçou o papel de pesquisadores dos próprios sujeitos pesquisados. A esses, cabia o papel de desenvolver o Programa e participar da formulação e análise das hipóteses. Não se pode afirmar que se tratou de uma Pesquisa-Ação no sentido estrito (Thiollent, 1988), pois não há como desconhecer que os princípios, em torno dos quais o Programa se organizou, não foram gerados em colaboração entre pesquisadores, professores e alunos, mas, pelo contrário, foram praticamente gestados pelos pesquisadores e levados ao campo, sob a forma de hipóteses e/ou questões. Ao lado desta abordagem, foi utilizada também a etnografia, cujo princípio básico é o de que os indivíduos organizem e interpretem suas situações de vida em função dos significados a elas atribuídos.

O processo de coleta de dados tomou como ponto de partida representações sobre os principais problemas da localidade, coletadas antes do desenvolvimento do Programa. O seu acompanhamento se deu através da observação participante. Por meio dessa, os pesquisadores participaram da capacitação dos professores regentes, da elaboração dos planos e do desenvolvimento de situações de ensino em sala de aula. Esse último, se justificou em razão de alguns dos professores locais, mesmo após o Programa de capacitação, transparecerem falta de disposição e motivação para o trabalho.
Para análise das hipóteses relativas ao significado da esquistossomose e das experiências com a doença, foram usados entrevistas, grupos focais e materiais didáticos (histórias, textos e testes) realizados durante e ao final da implementação do Programa. Esse caracterizou-se por envolver três níveis diferentes de ação. O primeiro, cuja duração foi de dez meses, referiu-se à apreensão imaginada do lugar e da doença, no plano figurativo, da impressão que eles produzem. Desse, seguiu-se para a representação do lugar e da doença, no plano simbólico, dos valores e crenças. O segundo nível concretizou-se em noves meses e consistiu na geração de informação crítica sobre o lugar e a doença e, por fim, o terceiro nível, que envolveu o exercício de intervenção deliberada sobre o lugar e sobre a doença, cujo tempo de realização abrangeu um ano e dois meses.

\section{Resultados e discussão}

\section{Imagens, representações e conhecimentos} sobre a água e a esquistossomose

Inicialmente, a fim de se verificar as representações e informações dos alunos sobre o córrego local, principal fonte de contágio da esquistossomose, foi solicitado que eles respondessem à seguinte indagação: “Quais os sentimentos e palavras que lhes ocorrem quando se lembram do córrego de Boa União?" As respostas dos alunos mostraram a presença expressiva dos substantivos: sujeira e poluição para caracterizar a água do lugar. De um total de 235 alunos, $60 \%$ mencionaram poluição, sujeira e lixo como as características que primeiro lhes ocorriam (Tabela 1, item 1). Apenas $16 \%$ citaram os elementos ligados à etiologia da esquistossomose, quando caracterizaram a água de Boa União (Tabela 1, item 3). Assim, o que aparece são imagens que conotam ambientes físicos deteriorados, sujos e malcheirosos, com a presença de muito lixo.

A relação entre a água e a esquistossomose pouco aparece nas respostas dos alunos. Estudos prévios (Gazzinelli et al., 1998), realizados em Boa União, antes do início do Programa de Educação, confirmam esse dado ao revelar que a esquistossomose não é reconhecida por alunos, professores e moradores como um problema importante, perdendo, enquanto prioridade, para outras doenças como diabete, hipertensão e problemas mentais, bem como para outros aspectos ligados à sua sobrevivência. Porém, deixam transparecer que "a xistose é uma doença que mata". 
Em seguida, no intuito de recolher representações e conhecimentos, agora sobre a esquistossomose e as condições necessárias para seu contágio, aos alunos foi sugerido criar, em grupos, histórias a esse respeito. Reunindo as respostas referentes aos itens 1, 3 e 5 da Tabela 2 , verifica-se que $77,7 \%$ dos grupos de alunos demonstraram não conhecer o conjunto de fatores responsáveis pela infecção pelo Schistosoma mansoni, considerando que atribuíram a causa dessa doença às águas sujas e poluídas com lixo e às formas de contágio de outras verminoses e, até mesmo, deixaram de mencionar a doença quando elaboraram suas narrativas. Além disso, as histórias narradas obedeceram a um padrão, uma vez que deixaram transparecer de forma acentuada, sentimento de culpa pelo ato de entrarem em contato com a água, como se verifica no seguinte texto:

“O menino estava passando mal por causa da água contaminada. E sua mãe levou ele para

Tabela 1

Imagens construídas pelos alunos de 3ạ a 8ạ séries sobre as coleções de água de Boa União.

\begin{tabular}{lrr}
\hline Imagens construídas & \multicolumn{2}{c}{ Alunos* } \\
& $n$ & $\%$ \\
\hline 1. Poluídas, sujas, com lixo, contaminadas & 140 & 60,0 \\
2. Contendo descarga & 21 & 9,0 \\
3. Contendo verme, descarga, caramujo, xistosa & 38 & 16,0 \\
4. Poluídas e com presença de verme & 36 & 15,0 \\
Total & 235 & 100,0 \\
\hline
\end{tabular}

* Alunos presentes no dia da atividade.

Tabela 2

Condições descritas nas histórias de grupos de alunos de 3ạ a 8ạ séries para a ocorrência de infecção pelo Schistosoma mansoni.

\begin{tabular}{lrr}
\hline Condições descritas & \multicolumn{2}{c}{$\begin{array}{c}\text { Grupos } \\
\text { de alunos* } \\
\text { n }\end{array}$} \\
\hline 1. Contato com qualquer rio, desde que poluído e sujo & 14 & 31,0 \\
2. Contato com rio contendo esgoto e fezes & 7 & 16,0 \\
3. Contato com esgoto e causas comuns a verminoses & 11 & 24,0 \\
4. Rio com descarga, caramujo, verme, água e esgoto & 3 & 7,0 \\
5. Não mencionam a doença & 10 & 22,0 \\
Total & 45 & 100,0
\end{tabular}

* Cada grupo era constituído de 3-5 alunos. consultar e o médico viu que ele está contaminado pela doença que se chama xistosa. Ele estava muito arrependido na sua doença e também muito triste porque ele tinha ido tomar banho contaminado pela água do poço. Ele decidiu que nunca mais ia sair para pescar e tomar banho no córrego porque água parada é lugar de caramujo".

Pelo menos na esfera escolar, é notável o arrependimento e a tendência dos sujeitos de autopunirem-se pela "norma" infringida. Também, a noção de que os sintomas da doença aparecem tão logo se abandona a fonte de contágio. O reconhecimento de todas as imagens, representações e noções sobre a água e a doença formaram a base para se elaborar a proposta de intervenção junto aos alunos e professores da escola local.

\section{Ensino com ênfase na cognição - a água e a esquistossomose}

Para que os alunos melhor compreendessem a questão da água, e nela se pensasse dentro de uma outra perspectiva que não a da deterioração, mas a de uma percepção sensorial mais positiva, foram trabalhados em sala de aula sob a forma de desenhos, pinturas e leituras os seguintes temas: "A solução está debaixo da terra”, "A água no planeta”, "A morte de um rio", "A vida sob a água", "A escassez da água no futuro" e "O interminável movimento da água". Já numa perspectiva local, os alunos identificaram fontes de água locais e discutiram sobre as redes de socialização que se tecem por trás de toda uma arquitetura construída por todos para resolver seus problemas de precariedade de água. A esquistossomose, embora não considerada pelos alunos, foi também abordada em aulas teórico-práticas, dentre as quais se destacaram a observação, no microscópio, das formas evolutivas do S. mansoni e a comparação do fígado de um camundongo normal com um infectado. Adotou-se esse procedimento porque admite-se que as formas de se relacionar com o ambiente e a doença, muitas vezes, não se traduzem em discurso verbal, devendo se constituir em objeto de investigação, de modo a se tornar inteligível para os sujeitos.

Após esse conjunto de estudos realizados pelos alunos, o próximo passo seria avaliar seus conhecimentos através de um questionário. Para fins de discussão acerca da postura frente aos principais problemas da localidade e, dentre esses, os de saúde, foram realizados grupos focais entre pesquisadores e professores e entre os primeiros e os alunos. 
Representações e conhecimentos sobre a esquistossomose após ensino, com ênfase na cognição

Através dos questionários, constatou-se que $66,5 \%(n=121)$ dos alunos permaneciam indicando as águas sujas e poluídas com lixo como causa da esquistossomose (Tabela 3, itens 1 e 4). Mesmo na resposta que liga a doença à causa de outras verminoses, ainda persiste a idéia do lixo na água como causa da enfermidade. Essa idéia da relação entre água e esquistossomose corroborava as noções dos alunos verificadas em grupo focal e em histórias desenvolvidas, respectivamente, antes e no início do Programa de Educação. Porém, verificava-se agora que não se tratava de qualquer coleção de água, mas de um tipo específico: "a água suja e poluída com lixo”. A relação sujeira/esquistossomose também foi encontrada por Noronha et al. (2000), nos seus estudos em área endêmica no Recôncavo Baiano. De forma equivalente aos estudantes de Boa União, a população do Recôncavo Baiano não consegue descrever o ciclo da doença e relaciona a transmissão da esquistossomose à água, mas deixa predominar a idéia de que são as águas sujas e poluídas que contribuem para a doença.

Essa persistente idéia relacionando lixo e doença pode ser explicada pelo fato de que, hoje, a idéia de sujeira não pode mais ser desvinculada dos agentes patogênicos (Douglas, 1976). Decorre daí, que a representação vinculando água, sujeira e esquistossomose pode ter originado do conhecimento das doenças microbianas ou viróticas comuns, que são transmitidas pela água suja. Estudos (Erickson, 1979; Hewson et al., 1988) mostram que o grau de persistência do senso comum obstruindo o conhecimento científico, é associado a seu grau de universalidade.

Verifica-se, ainda, pelos dados da Tabela 3, que $25 \%$ dos alunos mostraram-se capazes de indicar dois ou três dos fatores responsáveis pela doença (Tabela 3, itens 5 e 2). Quanto aos sintomas, verificou-se que $74 \%$ deles responderam parcial ou totalmente correto à questão referida na Tabela 4 (itens 1 e 2). Foram consideradas respostas corretas quando os alunos citavam dois ou mais sintomas (cólica, diarréia, inapetência etc.) e faziam referência à evolução da doença através da citação de sintomas (sangramento, barriga grande, baço grande etc.); parcialmente corretas quando citavam dois ou mais sintomas; nas respostas incorretas não citavam nenhum sintoma relacionado com a doença.

Em resposta aos grupos focais nos quais se discutiu os problemas vividos em Boa União,

\begin{tabular}{lrr} 
Tabela 3 & & \\
\hline & & \\
Condições descritas nos questionários dos alunos de 4ạ a 8ạ séries para ocorrência \\
de infecção pelo Schistosoma mansoni, após ensino com ênfase na cognição. \\
\hline Condições descritas & Alunos* & $\%$ \\
\hline 1. Água com sujeira e lixo & $n$ & 48,0 \\
2. Presença de lixo, caramujo e esgoto na água & 12 & 6,0 \\
3. Água, córrego e barro & 17 & 9,0 \\
4. Alimentos sem lavar, andar descalço e lixo na água & 25 & 13,0 \\
5. Descarga e caramujo/verme dentro do caramujo/fezes & 38 & 19,0 \\
6. Não compreenderam a atividade & 12 & 6,0 \\
Total & 200 & 100,0
\end{tabular}

* Alunos presentes no dia da atividade.

Tabela 4

Sintomas da esquistossomose citados nos questionários dos alunos de 4 a a $8 \underline{a}$ séries.

\begin{tabular}{lrr}
\hline Tipos de respostas & $\mathbf{n}$ & $\%$ \\
\hline Corretas & 53 & 27,0 \\
Parcialmente corretas & 96 & 48,0 \\
Incorretas & 50 & 25,0 \\
Total & 199 & 100,0 \\
\hline
\end{tabular}

os alunos citaram a poluição, os córregos sujos e o lixo e, em resposta aos problemas de saúde, mencionaram a dor na coluna, dor de cabeça, diabete, problema dos nervos e, como preocupações, outras enfermidades como a AIDS e o câncer. Observa-se que não houve mudança de postura frente à doença, mesmo após tê-la conhecido mais profundamente. Entretanto, a esquistossomose ainda era vista como uma enfermidade que poderia matar, embora, não tenha, ainda, chamado atenção dos moradores do lugarejo. Tendo sido esta a realidade, buscou-se hipotetizar junto aos professores e alunos sobre como a relação com a doença fora construída culturalmente, de modo a não ser considerada como anômala pelos que a vivenciavam.

Interpretando a relação anômala

frente à doença

A representação dos professores e alunos: “ $a$ esquistossomose mata, mas não se conhece ninguém que tenha morrido com a doença" parece 
exprimir, segundo os professores, o fato de que a causa de morte reconhecida pelo discurso biomédico, embora possa ser conseqüência da esquistossomose, nunca é mencionada como tal. Morre-se "de pressão alta”, "queda de cavalo”, “doença dos nervos”, “do coração” mas nunca de esquistossomose, conforme os próprios professores dizem. A esquistossomose pode provocar a morte, mas ela não é, em nenhuma instância, considerada uma doença letal. Considerar essa infecção como letal traz à tona uma concepção da doença que não está vinculada à esfera biomédica, e diz respeito a aspectos culturais possivelmente ligados à busca de mecanismos de controle da infecção.

Já a idéia difundida entre grande número de professores e alunos, de que "a xistose é uma verminose como outra qualquer" pode explicar o aparente descaso em relação a ela. Tal associação, se por um lado ameniza o perigo da doença, por outro, força os sujeitos a lidar, no dia-a-dia, com uma acentuada dispersão de fatores causais que podem ir desde beber água sem filtrar até pisar em fezes. A medida que se expande e diversifica o campo de atuação dos indivíduos para impedir a doença, mais numerosas se tornam as restrições às suas atividades cotidianas, dificultando a prevenção.

Outra questão, indicada pelos professores como um motivo que poderia estar interferindo na postura dos escolares frente à doença, seria a observação entre os seus parentes mais próximos ou vizinhos "de que uns pegam a doença e outros não”. Compartilhada por todos, tal idéia faz com que a doença se torne imprevisível, na medida em que, pragmaticamente falando, existe sempre a possibilidade de se "escapar" dela. Esse sentimento de surpresa frente a uma doença que "misteriosamente" acomete alguns e a outros, foi também detectado entre a população de Barragem da Pedra, região endêmica para esquistossomose, situada na Bahia (Alves \& Rabelo, 1998).

A representação "a xistose, de um lado, tem sintomas que surgem imediatamente e, do outro, quando você percebe, já está matando" abriga uma contradição cuja origem pode estar no confronto que se estabelece na estrutura conceitual dos sujeitos, entre o conhecimento comum, construído a partir da vida cotidiana e o conhecimento escolar. A noção de que a doença tem um quadro agudo e sintomas que são perceptíveis no início da enfermidade, provém do conhecimento escolar. Já a idéia de que quando percebida, a doença já está em fase avançada, origina-se de fatos observados entre os moradores e seus próprios discursos. Analisando tais noções dos alunos, observa-se que se os sintomas aparecem, imediatamente era de se esperar que o indivíduo os percebesse corporalmente, fato que não acontece. Pois, os sintomas percebidos pelos indivíduos, imediatamente após contato com a água contaminada com a larva do parasita, não podem ser atribuídos à esquistossomose (a não ser uma coceira sem conseqüências), porque há um período de incubação de 40-60 dias entre o contato com a água e as primeiras manifestações da doença, quando aparecem os ovos nas fezes.

A conseqüência desse modo de pensamento dos alunos, na prática, é que quando o conhecimento escolar se faz hegemônico, não há por que apelar para uma ação preventiva ou mesmo curativa por parte dos sujeitos, já que todos esperam pelos sinais agudos da doença. Nesse ponto específico, Rozemberg (1994), em seu estudo no Município de Conceição do Castelo, Espírito Santo, chegou a resultados semelhantes aos encontrados em Boa União. Lá, em Conceição do Castelo, os quadros assintomáticos da doença conduziram a idéias vinculadas unicamente ao discurso médico. Assim, não havia, para a população local, doença concreta (Rozemberg, 1994).

Analisando a noção de que a doença quando aparece já está matando, observa-se que em área endêmica, ela é crônica e, na maioria das vezes, os sinais e sintomas são benignos, assemelhando-se a outra verminose; entretanto, em poucos casos, a doença evolui em meses ou anos para uma forma grave que pode ser letal. Em síntese, se de um lado, a representação dos alunos é a de que os sintomas surgem rapidamente, e do outro, que a doença mata, embora não seja do conhecimento das pessoas, nos casos de morte no lugarejo a doença torna-se emblemática, adquirindo existência na medida em que representa uma idéia.

Outra causa apontada por professores para a ausência da doença nas falas dos alunos, é a crença de que "é na água poluída que se pega a esquistossomose”. Na ótica dos professores, se a fonte da esquistossomose é a mesma da de outras doenças, como das parasitoses comuns, não há porque conferir-lhe maior importância. Essa ligação entre poluição e doença pode ser compreendida em razão desses temas estarem na agenda do dia. Por fazer parte do ideário ambiental, tal tema vem compor um discurso globalizante, catastrófico e imobilizador. Face a essa tendência de globalizar um fenômeno localizado, Giddens chama atenção para o fato de que as reações do homem aos contextos de risco podem suscitar formas de pensar do tipo: "muito do que se passa no ambiente está fora de controle de qualquer um” (Giddens, 1991:136). 
Esse nexo "poluição e doença” parece estar relacionado também com a tendência de explicar a poluição, e algumas doenças dela decorrentes, pelos atos indevidos do homem; melhor dizendo, do "outro", que não é qualquer um, mas é aquele de nível social e educacional mais baixo. Para professores, prioritariamente, quanto mais desfavorecidas econômica e socialmente forem as realidades nas quais estão inseridos os diferentes grupos sociais, maior o descaso com os seus espaços físicos. Sabe-se, hoje, que comportamentos como jogar lixo e esgoto nos rios, poluindo-os, são tidos como moralmente desaprovados. Hoje, a idéia da conservação da natureza se impõe à moral do homem. Decorre daí, que falar da doença e do doente pode significar nomear e classificar os moradores de Boa União. Tal fato pode justificar a necessidade ou o desejo de interditar "o falar" sobre o doente. Assim, observa-se que há uma dimensão da ausência da doença que é a interdição. Uma evidência é que os nomes das pessoas doentes só foram obtidos depois de muita insistência por parte dos pesquisadores, ou através de fichas médicas dos profissionais de saúde.

Além dessas representações, as práticas dos sujeitos também compõem suas experiências. O ponto de vista tanto dos professores como o dos alunos se impõe como uma necessidade à sua sobrevivência e existência. As águas são meios simbolicamente estruturados, responsáveis pela transmissão dos habitus. Nesses espaços, se constrói um saber singular que se estende desde o conhecimento prático até a elaboração de conceitos e inculcação de valores (Bourdieu, 1998).

Em síntese, pode-se constatar, a partir das representações dos alunos, que os aspectos envolvidos na ocorrência da doença fazem dela algo irreal e contrafactual, uma vez que, alunos e professores acreditam que (1) esquistossomose mata, no entanto não conhecem ninguém que tenha morrido com a doença em Boa União; (2) a esquistossomose é como uma verminose qualquer; (3) alguns contraem a doença e outros não; (4) todas as águas sujas e poluídas com lixo são, supostamente, fonte de contágio; (5) os sintomas da doença ou são leves, surgindo tão logo abandonam a fonte de contágio ou, por outro lado, são graves, podendo ocasionar, inclusive, a morte. Além disso, desenvolvem na água, práticas ligadas a importantes dimensões da sua sobrevivência e existência. Todos esses resultados obtidos por meio do ensino com ênfase na cognição, sugerem que, conforme a experiência prévia dos sujeitos, a sua relação com os ambientes e com a doença não po- de ser modificada simplesmente pela aquisição de conhecimento, justificando-se um programa diferenciado de ensino.

\section{Intervindo na questão da água}

e da doença - o ensino com ênfase na experiência

Aspirando por uma postura mais realista frente à doença, deu-se início a um processo educativo, desta vez não com base na cognição, mas com ênfase na própria experiência dos sujeitos. Propôs-se a eles uma investigação, uma pergunta a ser respondida. Para respondê-la, os alunos desenvolveram um conjunto de atividades que guardaram entre si o mesmo empenho, qual seja o de desorganizar as experiências iniciais dos alunos através da vivência de novas experiências educativas e suas conseqüências (Bachelard, 1996).

Pretendeu-se trabalhar com o conceito de experiência reflexiva conforme formulado por Dewey (1952). Diante de uma experiência reflexiva, os sentimentos são de perplexidade, confusão e dúvida devido ao fato de que os sujeitos estão envolvidos em uma situação incompleta, cujo caráter não seria ainda plenamente determinado. Em torno dessa situação, fazem uma tentativa de interpretação dos dados, atribuindo-lhes uma tendência para produzir certas conseqüências. Realizam cuidadosos exames envolvendo observação, inspeção, exploração e análise. Por fim, põem à prova as hipóteses formuladas. Tudo isso transforma o ato de pensar em uma experiência educativa (Dewey, 1971).

O ensino com ênfase na experiência envolveu seis atividades. Duas delas possuíam natureza subjetiva e interativa: uma encenação na qual dois rios dialogam sobre suas mazelas ambientais e sociais e, conversas informais sobre vivências na água. Quatro atividades caracterizaram-se pela ênfase na análise de situações concretas e objetivas. Eram atividades que convidaram os alunos a questionar muitas das evidências sobre as quais construíam o conhecimento comum, abrangendo: trabalho de campo para observação de caramujos em águas claras; investigação em cartório para obtenção da "causa mortis" nos últimos cincos anos; entrevistas com médicos sobre mortes que poderiam ser conseqüência da esquistossomose e entrevistas com portadores da enfermidade. A avaliação desse ensino com base na experiência se deu através de dois instrumentos: o relatório do trabalho de campo, e um texto provocativo em torno do qual os alunos eram induzidos a testar seus conhecimentos e incitados a 
posicionarem-se, aplicando ensinamentos adquiridos.

Representações, conhecimentos e postura dos alunos com relação à água

e à esquistossomose após ensino com ênfase na experiência

Os relatórios, embora diversificados e pessoais, possuíam também muitas idéias em comum. Apresentaram uma forma original e, num certo sentido, até provocadora. Segue um exemplo que ilustra idéias normalmente presentes em outros relatórios:

"A xistose é uma doença muito perigosa, pois muitas das vezes pode nos levar à morte. $O$ caramujo sobrevive em lugar abundante, onde há luz, oxigênio, água limpa e água corrente fraca, lodo e plantas. As plantas servem para eles ficarem nelas e se alimentarem. O verme da xistose entra no caramujo, ele é miracídio, depois ele cresce e já não quer ficar dentro do caramujo, ele sai em forma de cercária. E quando o homem vai defecar ele elimina fezes com ovos de larvas, esses ovos podem transformar em grandes quantidades de larvas. Mas não são todas as águas que contém esse verme. Por exemplo, um poço de água pode não existir, mas quando vem uma chuva e traz enchentes, traz esse verme, e outro exemplo é um pássaro que pode vir tomar água em um rio onde não tem, mas ele tenha encostado em algum lugar que tenha este caramujo, ele traz prá dentro do poço que não tinha antes. Então não devemos deixar cisternas destampadas para que eles não reproduzam, e nem defecar perto dos rios porque se não as enchentes levam para o rio e vão trazer para si a própria morte".

Percebe-se, logo de saída, a representação de que a esquistossomose é uma doença perigosa que pode matar. A presença da morte é uma constante. A idéia da letalidade da doença convive com a realidade vivida. É, nessa relação do imaginário com o real, ou seja, de uma doença que, na mente dos alunos mata, mas na concreticidade do cotidiano não, que os alunos buscam exercer algum controle sobre ela. Menendez (1998), afirma que, nesses casos, não se deve tratar a representação como um saber a ser substituído, mas como uma prática de prevenção construída, intersubjetivamente, na tentativa de reagir à enfermidade.

Com relação à representação de que a contaminação pela doença se daria pelas águas sujas com lixo, observa-se que ela foi substituída pela noção de que a enfermidade seria devida à inexistência de esgoto no lugar, à presença de fezes na água e de caramujos contaminados com cercárias. Sobre esse tema, o relatório demonstrou que os alunos eram capazes de interrelacionar os fatores objetivos responsáveis pelo fenômeno da doença, discriminar situações que caracterizam exposição a fatores de risco, relativizar essas condições imprimindo-lhes um tom de incerteza no que tange às possibilidades de contaminação e descrever a ecologia da doença. Além dessas competências demonstradas pelo relato anterior, os alunos passaram a reconhecer a multicausalidade determinante da endemia, atribuindo a explicação causal não apenas a um fator como se constata pelo texto abaixo:

"O povo de Boa União pega muita xistose porque tem águas paradas e limpas aparentes, $e$ nestas ocasiões que as pessoas pegam xistose nós devemos evitar o contato com este tipo de problema. Hoje em Boa União, tem água tratada, a caixa d'água da cidade é fechada então evita este tipo de doença, mas nas fazendas vizinhas não tem água tratada, então estas pessoas correm o risco de pegar a xistose mesmo filtrando $e$ fervendo a água, porque algumas pessoas entram dentro do córrego com esgoto e caramujos para pescar, tomar banho, essas pessoas são principalmente as crianças".

Importante notar ainda, que grande parte dos relatos, como também o que se segue, exibem importante ponto em comum - neles a explicação sobre a doença envolve a interação simultânea e interdependente entre os vários aspectos que a compõem. Seguem dois pequenos textos para efeito de ilustração:

"Um dos principais motivos pela grande contaminação da xistose é a pobreza, a falta de rede de esgoto e a falta de prevenção".

"A causa da xistose é que não temos rede de esgoto, muitos não têm banheiro então quando chove a água carrega as fezes deixando em alguns recantos dos rios".

Ainda, nesta linha de raciocínio segundo a qual os componentes da doença aparecem interligados, o relatório a seguir é revelador. Embora à primeira vista apareça desorganizado, olhando-se através da perspectiva e lógica científicas, em momento algum se observa a sua simplificação.

"O caramujo fica em água limpa, que aparece limpa. A xistose existe em Boa União por causa da plantação de arroz, que não tem roupa própria, as pessoas que plantam arroz não cuidam da saúde, e de seis em seis meses trata, que é obrigatório fazer isso. A água em Boa União não é tratada, por isso que tem muitas pessoas com xistose, não filtram a água. Aqui muitas pessoas defecam no chão, por não ter o sanitário eles defecam no chão, aí vem a chuva 
e leva para a água do córrego. E o trabalhador que tem que andar na água e pega a cercaria e a doença"

Nesse texto, as partes do todo são dispostas formando uma construção complexa. Não apenas com relação à forma. Mas, sobretudo, no que concerne à lógica em que se baseia tal construção: a da complexidade. O conceito de complexidade aqui utilizado é cunhado por Morin (1996), e está relacionado à concepção de que há algo relacionado ao ato de pensar. Para o autor, a complexidade representa uma possibilidade de pensar através das inter-retroações, contradições, ambigüidades e incertezas por meio de uma constante tensão entre o racional e o empírico, e entre a verificação e a imaginação.

Por meio de um texto provocativo, contendo sentenças do tipo "a xistose não é um problema sério", "é só tomar o remédio que sara", "é um verme qualquer", pronunciadas pelos alunos no início do programa, foi possível averiguar a sua capacidade argumentativa. Notouse deslocamentos no modo dos alunos se posicionarem frente à doença. Sessenta e dois por cento dos alunos chegaram a refutar tais afirmações. E agora, de modo mais preciso, observou-se também um deslocamento da posição dos sujeitos frente à doença - de uma reação anômala de "interdição sobre o falar da doença”, evoluiu-se para uma reação "normal”, visto que, após ensino com ênfase na experiência, eles manifestaram-se afirmando ter a infecção pelo S. mansoni uma forma branda que, se não identificada a tempo pelo exame de fezes, pode agravar; e mais, que, em sua forma grave, traz sérias conseqüências tais como a retirada do baço e hemorragia; que a doença tem cura se identificada a tempo; que nos casos em que é tratada deixa de ser perigosa; que é de difícil diagnóstico (sem o exame de fezes) e pode ser enfrentada pelo saneamento básico, organização coletiva, exame médico freqüente, informação e diferentes opções de lazer.

\section{Considerações finais}

Examinando algumas das representações dos sujeitos após o desenvolvimento do programa, observa-se, agora mais de perto, as conseqüências da Educação com ênfase na cognição. A partir dela, foram produzidas respostas que demonstraram acúmulo de conhecimento acerca da etiologia e evolução da doença, embora esse conhecimento não tenha conduzido a um questionamento de algumas representações dos alunos. Detectou-se também que não foi construída uma nova postura com relação à doença.

No ensino com ênfase na experiência, observou-se, ao lado de um conjunto de competências descritas, o desenvolvimento de um novo modo de se fazer frente à doença. Para que isso se viabilizasse, foi preciso observá-la, indiretamente, por métodos críticos e voltados para a superação dos obstáculos epistemológicos (Bachelard, 1996), a saber: "a xistose mata”, "a xistose se pega em águas sujas e poluídas", "não se conhece ninguém que tenha morrido com a doença", "a doença traz para si e para os outros a própria morte”. Nesse sentido, é importante assinalar que o ato cognoscente se realizou no momento em que a doença foi tratada como experiência em torno da qual culturalmente havia sido construído, de modo coletivo, o fenômeno da interdição sobre "o falar da doença".

$\mathrm{O}$ ensino com base na experiência mostrou que o modo de os sujeitos se colocarem frente à doença, não deve ser visto como contrário aos métodos “corretos" de prevenção e controle das enfermidades. Ao invés disso, devem ser considerados em sua positividade e orientados em favor da manutenção da saúde pela população.

Tal ensino com base na experiência mostrou, também, que os conhecimentos embora contraditórios, ambíguos e imprecisos, constituem fruto de uma construção cultural e são empregados por um determinado grupo social para dar respostas aos desafios e situações de sua vida cotidiana. Torná-los equivalentes a uma "falta de compreensão", "desconhecimento" ou "falta de consciência" por parte das camadas desfavorecidas sócio-educacionalmente, leva a se interpretar como algo inócua a ação educativa, já que absolutamente dissociada da experiência dos sujeitos com a doença. 


\section{Agradecimentos}

Desejamos agradecer o apoio do Conselho Nacional de Desenvolvimento Científico e Tecnológico, e da Fundação de Amparo à Pesquisa do Estado de Minas Gerais, que tornaram possível o desenvolvimento deste trabalho.

\section{Referências}

ALVES, P. C. \& RABELO, M. C., 1998. Repensando os estudos sobre representações e práticas em saúde/doença. In: Antropologia da Saúde: Traçando Identidades e Explorando Fronteiras (P. C. Alves \& M. C. Rabelo, org.), pp. 107-231, Rio de Janeiro: Relume Dumará.

BACHELARD, G., 1996. A Formação do Espírito Científico: Contribuição para uma Psicanálise do Conhecimento. Rio de Janeiro: Contraponto.

BOURDIEU, P., 1998. O Poder Simbólico. 2a Ed. Rio de Janeiro: Bertrand Brasil.

CORREA-OLIVEIRA, R., 1994. Levantamento Prévio da Prevalência da Esquistossomose e do Número de Caramujos Infectados das Regiões de Boa União, Nova União e Patrimônio Velho. Belo Horizonte: Centro de Pesquisas René Rachou, Fundação Oswaldo Cruz.

DEWEY, J., 1952. Democracia e Educação. São Paulo: Nacional.

DEWEY, J., 1971. Experiência e Educação. São Paulo: Nacional.

DOUGLAS, M., 1976. Pureza e Perigo. 10a Ed. São Paulo: Perspectiva.

ERICKSON, G., 1979. Children's conceptions of heat and temperature. Science Education, 63:221-230.

FUNASA (Fundação Nacional de Saúde), 2002. Dados sobre Número de Pessoas Infectadas pelo Schistosoma mansoni, por Estado no Brasil. 23 Janeiro $2002<$ http://www.funasa.gov.br>.

GASTALDO, D., 1997. É a educação em saúde "saudável”? Educação \& Realidade, 22:147-168.
GAZZINELLI, A.; GAZZINELLI, M. F.; CADETE, M. M. M.; PENA FILHO, S.; SÁ, I. R. \& KLOOS, H., 1998. Sociocultural aspects of schistosomiasis mansoni in na endemic area in Minas Gerais, Brazil. Cadernos de Saúde Pública, 14:841-849.

GIDDENS, A., 1991. As Conseqüências da Modernidade. 2a Ed. São Paulo: Editora Unesp.

HEWSON, P. \& HEWSON, M., 1988. An appropriate conception of teaching science: A view from studies of science learning. Science Education, 72:597-614.

MENENDEZ, E. L., 1998. Antropologia médica e epidemiologia: Processo de convergência ou processo de medicalização? In: Antropologia da Saúde: Traçando Identidade e Explorando Fronteiras (P. Alves \& M. Rabelo, org.), pp. 71-93, Rio de Janeiro: Relume Dumará.

MORIN, E., 1996. O Problema Epistemológico da Complexidade. 2a Ed. Lisboa: Europa-América.

NORONHA, C. V.; BARBOSA, A. G.; SOUZA, Y. M. \& LAGO, R. S., 2000. Estudo da esquistossomose mansoni na perspectiva do gênero em uma área do Recôncavo da Bahia - Brasil. In: Doenças Endêmicas: Abordagens Sociais, Culturais e Comportamentais (R. B. Barata \& R. Briceño-León, org.), pp. 183-197, Rio de Janeiro: Editora Fiocruz.

ROZEMBERG, B., 1994. Representação social de eventos somáticos ligados à esquistossomose. Cadernos de Saúde Pública, 10:30-46.

THIOLLENT, M., 1988. Metodologia da Pesquisa-Ação. 4a Ed. São Paulo: Cortez.

Recebido em 24 de setembro de 2001

Versão final reapresentada em 6 de março de 2002 Aprovado em 16 de abril de 2002 